\title{
Effectiveness of Health Education to Improve Oral Care of Primary School Children in A Rural Community of Pakistan
}

\author{
Maaz Ahmad $^{1^{*}} \quad$ Muhammad Hussain $^{2} \quad$ Muhammad Afzal $^{2} \quad$ Syed Amir Gilani ${ }^{3}$ \\ 1. BS Nursing, The University of Lahore, PO box 54000, Lahore, Pakistan \\ 2. Assistant Professor, the University of Lahore, PO box 54000, Lahore, Pakistan \\ 3. Professor, the University of Lahore, PO box 54000, Lahore, Pakistan
}

\begin{abstract}
Oral health is an integral part of human general health. "Oral health is the beauty of the oral cavity, which includes teeth, tissue and its supporting structure, the overall health promotion is necessary but focuses on oral health is most important, it is primarily aiming to prevent from oral disease by health education. Methods: A quasiexperimental, quantitative, before and after study design was conducted among the students total $(n=56)$ in the primary school of Ali Raza Abad Raiwind Road Lahore, Pakistan from September 2018 to December 2018. The educational intervention involve four meeting about oral hygiene in which the researcher educate the students about poor and good oral hygiene, prevention of disease which are caused by poor oral hygiene and appropriate way of tooth brushing lead to good oral health. Results: A total of 56 children participated in the study, the majority of the participants were boys $41(73.2 \%)$. The mean before the educational intervention is 5.83 (Standard deviation 3.80) and after the educational intervention is 7.86(Standard deviation 3.36). The mean difference between the two mean is 2.01 . There is a statistically significant difference before and after the educational intervention. The educational intervention is highly effective because the significant value is 0.00 Conclusions: The result of the study shows that oral hygiene can be improved by educational intervention and by proper techniques of tooth brushing.
\end{abstract}

Keywords- Improve oral care. Oral health education.

DOI: $10.7176 / \mathrm{JEP} / 11-7-03$

Publication date:March $31^{\text {st }} 2020$

\section{Introduction}

It is truly said that Health is wealth. Health is a blessing of Almighty Allah. Oral health is an integral part of human general health. "Oral health is the beauty of the oral cavity, which includes teeth, tissue and its supporting structure, free of disease and ideal functioning of the oral cavity and its tissue, by which the high level of self-worth and inter-professional relationship are preserved (Dahl, 2011). The finding indicated that the prevalence of toothbrushing behavior in some countries including China is $40 \%, 44 \%$, Jordan $31 \%$, and Burkina is $36 \%$. In some developed countries including the USA and Canada, the prevalence rate differs among boys and girls. On the other hand, In Mexico, the great difference has been observed in the prevalence rate in school-age children which is $57 \%$ to $82 \%$. The great variability can be found of the prevalence in both less developed and developed countries (Cosanova- Rosado et al., 2014).A study conducted by Ali et.al., (2012) in which majority of the people use toothpaste and toothbrush but most of the people $(88.0 \%)$ also use finger and miswak for tooth cleaning. Another study stated that some people like to clean their mouth to use tooth powder (5.76\%), Miswak (2.64\%), and (95.4\%) toothbrush for cleaning their mouth (Younus \& Qureshi, 2016).During childhood, health behavior can easily be changed as compared to the stage of adolescence. The school-aged children are interested to accept and maintain positive health behavior. The impacts are long-lasting of those habits which are established earlier in childhood. It's easy to adopt good oral health behavior early in childhood because it is difficult to change the harmful behavior after adolescence (Mohamadkhah, Shokravi, Karimy, \& Faghihzadeh, 2014). Oral health education and interventions of oral hygiene are necessary for those children who do not brush and floss, also for the prevention of oral disease, because health education is very important to measure for the prevention of oral disease and to improve oral health (Mohamadkhah et al., 2014). Oral health education programs continue to be developed and implemented in school settings, meaning that the critical assessment and summarization of that evidence is important to provide clinicians, stakeholders and decision-makers with needed information about the costeffectiveness of education based oral health programs (Stein, Santos, Hilgert, \& Hugo, 2018). The world health organization stated that oral health education should be on the behavior and condition of school children by which the children can eradicate the risk of oral disease and promote oral health. With the help of oral health education, students can change their toothbrushing habits, use of fluoride and improve their good diet among other strategies. In oral health education, different types of resources are used which include lectures, flipcharts, videos brochure, and presentation. The teaching of brushing techniques and application of fluoride is also very helpful (Stein et al., 2018).

Lecture method is very useful because many students are getting knowledge at the same time. The lecture method is easy to apply, convenience and adopted a huge amount with specific teacher plan, place, time, and very 
flexible (Habib, Shiraz, Naseri-Kouzehgarani, Hooman, \& Reza 2016). The overall health promotion is necessary but focuses on oral health is most important, it is primarily aiming to prevent from oral disease by health education. Oral health care should be implemented not only in primary school children throughout life. To improve the oral health status of children and for the development of proper oral health knowledge, attitude, beliefs, and healthy lifestyles, there are many types of health education programs are organized. It is stated that tooth brushing exercise, activities related to diet and nutrition and flossing of teeth is the part of oral health education in many countries (Jurgensen \& Petersen, 2014).The aim of oral care education and well-made intervention may improve the consciousness level of school children which may bring change in oral health behavior which leads to better oral health (Sanadhya et al., 2014).Good oral health and daily oral hygiene are interconnected to each other while neglecting oral hygiene is leading to disease like dental caries, gingivitis and many others (Jacobsson, 2013). On the other hand, many lifestyle behaviors including extra food, drinks which are high in sugars, smoking a cigarette and drinking alcohol are affecting oral health but the strategies of oral health promotion are supporting preventive intervention. That is why it is possible to control all these behavior in school settings to correct the physical environment and apply education in oral health through school policies (Reddy \& Singh, 2017).

\section{Literature Review}

Many factors influence the pattern of oral hygiene in children. A study was conducted in which 1,120 children do not know the pattern of oral hygiene and perform irregularly. The prevalence rate of dental plaque among those children who do not perform oral hygiene regularly was $37.0 \%$ (Cascaes et al., 2015).

National and international studies have shown that there is a great change in children habits and they are developing new knowledge through health education in the school environment. A study conducted to promote oral health through the help of lectures and other activities. The children were enrolled in preschool and elementary school. The result showed that the children who brush their teeth deficiently decrease from $20.7 \%$ to $4.1 \%$ and those who brush their teeth regularly were decreased from $62.1 \%$ to $49.7 \%$, the good hygiene index increased from $8.9 \%$ to $32 \%$ (Carvalho et al., 2016).

School is the best place to promote health and prevent disease across the whole world. Regular tooth brushing with fluoridated toothpaste are very essential for the children oral health and healthy lifestyle. When the parents and school both are involved in oral health promotion it can be easier to promote oral health and prevent oral disease. A study conducted in Southern Thailand which show the good effect of fluoridated toothpaste which was provided by the teacher of the school to improve school oral health program. The study showed that there is a great impact on the incidence of dental caries in the school children of Thailand. The incidence rate of dental caries decreases up to $34 \%$ for all school which participated in the study and up to $41 \%$ for more cooperative students involved in the study (Pithpornchaiyakul, S., hintao, J., Jurgensen, N., \& Ellwood, R., 2015).

It is suggested that Before and after the oral health education there was no gender difference in knowledge, attitudes, and practice. The knowledge about the causation of dental carries was a severe increase from $9.5 \%$ to $51 \%$ and knowledge about floss was an increase from $12 \%$ to $58.6 \%$ at the end of the study. At the end of 12 months, the knowledge about different oral disease increased from $34.5 \%$ to $54.5 \%$ and the knowledge about bleeding of the gums increase from $47 \%$ to $62 \%$. The significance of the individual responsibility of performing self-oral health was $53 \%$ to $87 \%$. Oral health education provided by a school teacher or oral health professional in developed countries, which has usually improved the student's oral health knowledge, attitudes, and oral hygiene status. The studies have focused on effects and the process of teaching training in oral health education and the session of oral health education in a school which affect the impact of the program and the outcomes between the children (Sanadhya et al., 2014).

Five studies were conducted in the meta-analysis in which the result showed significant differences in the outcome of dental plaque which is caused by unhealthy oral hygiene, supporting interventional group. Some studies showed a positive effect of oral health education on dental plaque in the short term. On the other hand, the studies did not show significant changes between the groups on the level of plaque, which is clarified by the number of applicants in the study group. Another study conducted by Chandrashekar and D'Cruz which says that oral health education is the important objective to prevent oral disease and promote oral health but the result showed that there is no effect of health education on gingivitis reduction which is also caused by unhealthy hygiene (Santos, Stien, \& Hugo. 2018).

A study conducted in which $534 \& 538$ children were observed before and after the intervention but there were no better differences were found in the demographic characteristic of study population among pre and postintervention, the prevalence of dental caries during pre-intervention was found to be $48.3 \%$ but there was no significant effect after the intervention. On the other hand, the significant decrease in debris is $78.3 \%$ to $54.1 \%$ and the reduction in stage- 1 plaque was from 75.5 to $66.5 \%$ in the oral cavity in post-intervention. There was no significant improvement in the gingival health status after the intervention (Raj, Goel, Sharma, \& Goel, 2016).

A study showed that oral health education is much effective and improving poor oral health hygiene levels in the school settings in which different methods can be used such as lecture method, practice, intervention, model 
or brochure. The same result was also found in test score in each group and study showed simultaneously improving in oral health hygiene and children's knowledge about oral health. so, it is understood that education can easily motivate school children and also the teaching of brushing techniques is a complex and time-saving procedure (Demiriz et al., 2018).

A study is conducted in which only $4.1 \%$ of the children used to brush their teeth daily before the intervention, which is improving significantly to $9.9 \%$ after the intervention. Around $14 \%$ of the children before the intervention never used to brush the teeth in their lifetime, which decreased to $7 \%$ after the intervention. The rinsing of the mouth after taking the meal is significantly increased from $39.5 \%$ to $52.2 \%$ (Raj et al., 2016).

Studies have shown that the improvement of oral hygiene level and significant reduction of dental caries in preschool and school children can occur by proper tooth brushing (Macpherson, Anopa, Conway, \& Mcmahon, 2014). Another study conducted in which tooth brushing have been focused primarily on their effectiveness of oral hygiene by manual or electric toothbrushes, or with some kind of modification in oral hygiene (Rosema et al., 2014). Other studies showed that tooth brushing has its own role as an independent variable in oral disease, some studies also explored the proper way of toothbrushing and how to modified tooth brushing behavior (Medina-solis, E.C et al., 2014).

The study of Casanova-Rosado et al., stated that the preventive oral care is performed by a healthcare professional and dental hygienists but the individual oral hygiene is also the great importance if it is conducted at home settings. The daily oral hygiene of an individual is necessary to remove the bacterial biofilm by proper tooth brushing (Cosanova- Rosado et al., 2014).

\section{Methodology}

Quasi-experimental with pre and post-intervention phases using the quantitative method of data collection. Data was collected from 56 primary school students in community of Ali Raza Abad using convenient sampling technique. A well adopted questionnaire was used, Participants were well informed. Data was analysed through SPSS 21. The study was 4-5 month (September 2018 to December 2018).

\section{Results}

Section 1

This section represents the demographic characteristics of the participants whereas 56 children participated in the study, the majority of the participants were boys as compared to girls. Table and Figure \#1, shows the distribution of Age and Gender male and female enrolled in the study, 41(73.2\%) were boys and 15(26.8\%) were girls. Age categories of the students were, $53.6 \%$ have 9 years of age, $27.7 \%$ have 10 years of age, $17 \%$ have 11 years of age and $1.8 \%$ have 12 years of age are participated.

Table 1: Demographic Characteristic of participants.

\begin{tabular}{|c|c|c|}
\hline Gender & Frequency $(\boldsymbol{f})$ & Percentage (\%) \\
\hline Boys & 15 & $26.8 \%$ \\
\hline Girls & 41 & $73.2 \%$ \\
\hline Total & $\mathbf{5 6}$ & $\mathbf{1 0 0 \%}$ \\
\hline Age & Frequency $(\boldsymbol{f})$ & Percentage (\%) \\
\hline 9 years & 30 & 53.6 \\
\hline 10 years & 15 & 27.6 \\
\hline 11 years & 10 & 17.0 \\
\hline 12 years & 1 & 1.8 \\
\hline Total & $\mathbf{5 6}$ & $\mathbf{1 0 0}$ \\
\hline
\end{tabular}

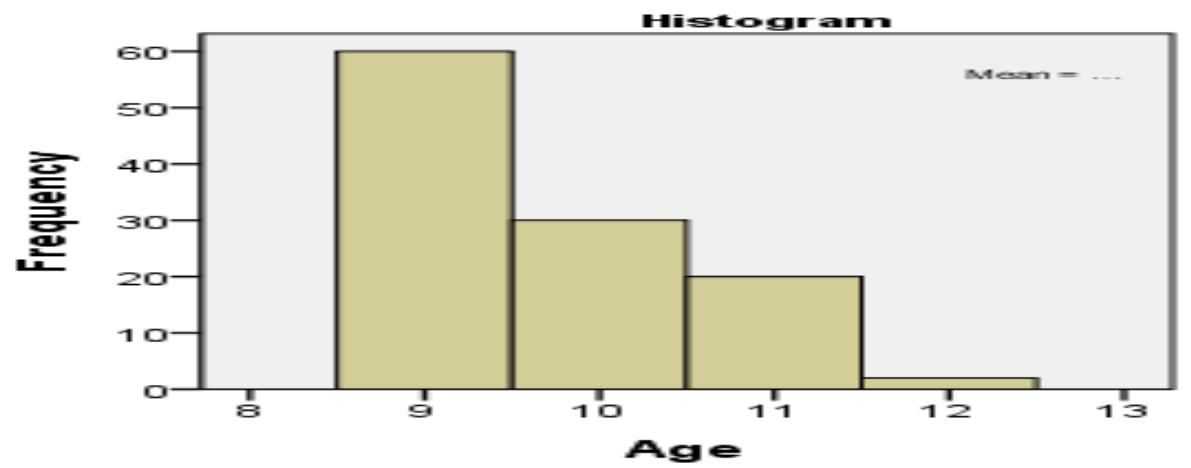

Fig 1: Percentages of knowledge and practice 


\section{Section 2:}

Section 2 represents the frequency and percentage between pre and post interventional education of primary school children.

Table 2: Pre and Post data of educational intervention.

\begin{tabular}{|c|c|c|c|c|}
\hline & \multicolumn{2}{|l|}{ Pre } & \multicolumn{2}{|l|}{ Post } \\
\hline Knowledge of primary school children about oral care & Frequency & $\%$ & Frequency & $\%$ \\
\hline $\begin{array}{l}\text { 1. Put a small amount (small pea or rice grain) of toothpaste on } \\
\text { the brush. }\end{array}$ & 34 & $60.7 \%$ & 47 & $83.9 \%$ \\
\hline 2. Brush teeth internally & 26 & $46.4 \%$ & 33 & $58.9 \%$ \\
\hline 3. Brush teeth externally & 39 & $69.6 \%$ & 48 & $85.7 \%$ \\
\hline 4. Brush front teeth (incisors and canines) & 35 & $62.5 \%$ & 49 & $87.5 \%$ \\
\hline 5. Brush posterior teeth (premolars and molars) & 25 & $44.6 \%$ & 42 & $75 \%$ \\
\hline 6. Brush contact surface of the teeth & 24 & $42.9 \%$ & 41 & $73.2 \%$ \\
\hline 7. Brush teeth of the upper dental arch & 36 & $64.3 \%$ & 47 & $83.9 \%$ \\
\hline 8. Brush teeth of the lower dental arch & 48 & $85.7 \%$ & 56 & $100 \%$ \\
\hline 9. Brush surface of the tongue & 15 & $26.8 \%$ & 34 & $60.7 \%$ \\
\hline 10. Rinse mouth with water at least once & 37 & $66.1 \%$ & 51 & $91.1 \%$ \\
\hline
\end{tabular}

Table No. 3 Average Pre and Post Interventional Mean

\begin{tabular}{|l|l|l|l|l|}
\hline $\begin{array}{l}\text { Average Pre } \\
\text { Mean }\end{array}$ & Average Post Mean & Average Pre SD & Average Post SD & $\begin{array}{l}\text { Difference between } \\
\text { Means }\end{array}$ \\
\hline 5.839 & 7.86 & 3.803 & 3.365 & 2.017 \\
\hline
\end{tabular}

Average pre and post interventional mean and Standard Deviation is mentioned in table 14. Before interventions the knowledge score was 5.839 while post interventional knowledge was 7.86 . The difference between pre and post score was 2.017

Section 3:

This section shows the normality of the data.

Table No. 4 Test of Normality

\begin{tabular}{|c|c|c|c|c|c|c|}
\hline Tests of Normality & \multicolumn{3}{|c|}{ Kolmogorov-Smirnov } & \multicolumn{3}{|c|}{ Shapiro-Wilk } \\
\hline Total & Statistic & $\mathrm{df}$ & Sig. & Statistic & $\mathrm{df}$ & p-value \\
\hline Pre & .226 & 56 & .000 & .798 & 56 & $<0.001$ \\
\hline Post & .327 & 56 & .000 & .669 & 56 & $<0.001$ \\
\hline
\end{tabular}

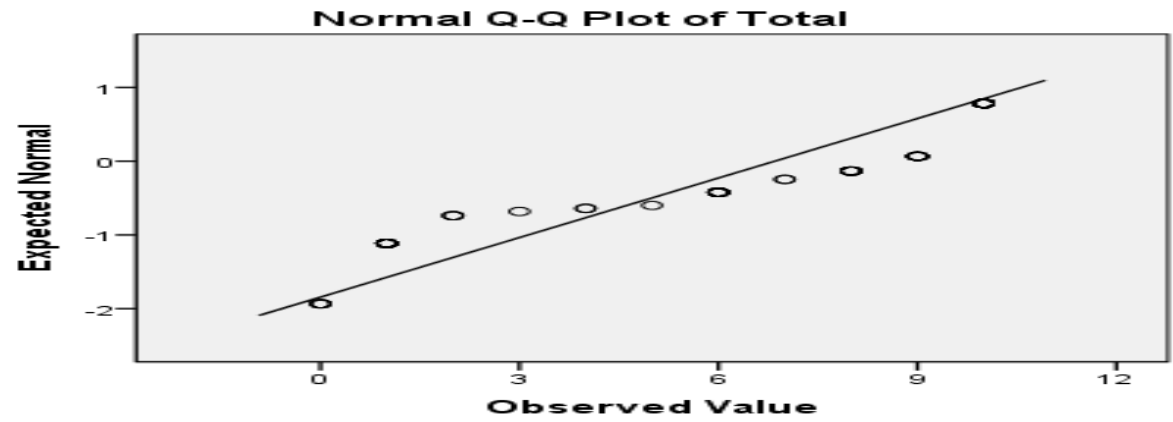

Fig 2: Test of Normality

According to table\#4 and Fig\#2 the data is not normally distributed.

\section{Section 4:}

The non-parametric Wilcoxon Sign rank Test is used in the study

Table No. 5 Wilcoxon Sign rank Test

\begin{tabular}{|l|l|l|l|l|l|l|l|l|}
\hline & No. of participants & Mean & SE & SD & Median & IQR & $\begin{array}{l}\text { Wilcoxon Sign rank } \\
\text { Test }\end{array}$ & $\begin{array}{l}\text { P- } \\
\text { value }\end{array}$ \\
\hline Pre & 56 & 5.83 & 0.5 & 3.80 & 6 & $10-1$ & \multirow{2}{*}{4.926} & $<0.001$ \\
\hline Post & 56 & 7.86 & 0.4 & 3.36 & 10 & $10-6.2$ & 4.96 & $<$ \\
\hline
\end{tabular}

The total mean of school children before the educational intervention is 5.83 (Standard deviation 3.80) and after the educational intervention is 7.86(Standard deviation 3.36). The mean difference between the two mean is 2.01. There is a statistically significant difference before and after the educational intervention. The educational intervention is highly effective because the significant value is 0.00 and that is why the null hypothesis will be rejected and alternative hypotheses will be accepted. 


\section{Discussion}

The present study shows that oral health education has a great impact on children's oral health as is evidenced through the post data result of the students in which the $\mathrm{p}$-value indicated the positive effect which is $\mathrm{p}<0.01$. On the other hand, the result also shows that the most important was the curriculum and content of oral health education, the post data results of the students indicated that factors such as the brushing techniques in the educational intervention play a vital role in improving the oral health of the children. Mean before the educational intervention was 5.83 which is significantly increased after the effective educational intervention to 7.86 . That is why the null hypothesis is rejected in favor of the alternative hypothesis. The result of the similar study shows that there was also a significant improvement of appropriate behavior related to tooth brushing in which the mean before the intervention was 4.43 and after the learning intervention there was a significant increase in the mean number which was 8.56. The significant value of the study was $(\mathrm{p}=0.0083)$ (Sigaud, Santos, Costa, \& Toryama, 2017).

Another study finding shows a positive impact of health education in which only $4.1 \%$ of the school children used toothbrush daily before the intervention, which is improved significantly to $9.9 \%$ after the educational intervention. Before the educational intervention around $14 \%$ of the school children never used to brush the teeth in their lifetime, but after the educational intervention, the ratio decreased to $7 \%$. The rinsing of the mouth lunch or dinner is significantly increased from $39.5 \%$ to $52.2 \%$ (Raj et al., 2016).

The key finding of the present study is improved oral care regarding oral hygiene behavior through educational intervention. Lecture demonstration method used in the present study to teach oral health education to the primary school children which are similar to other studies in which the school children submitted to preventive oral health educational program have better oral health status as compared to those children who are not joining oral health educational program. A similar study conducted by Thomas et al in which educational intervention showed significant improvement in different oral habits and hygiene of children. A study by Haleem et al. has concluded that various strategies like teacher-led, dentist led and peer-led of oral health education are similarly effective in improving the oral health knowledge and oral hygiene status of children (Haleem, A., Siddiqui, M. I., \& Khan, A. A. 2012).

In the present study, an oral health education program has a great impact and effectiveness on children oral hygiene practice. In this study, most of the students were not using toothbrush because they don't have a toothbrush, and it is eventually up to their parents to provide hygiene supplies to their children and take them to the dentist twice a day. The finding of the similar study shows that parent's involvement is necessary if they want good oral hygiene of their children. Parents play a great role in their children's oral health education, if there is low oral health literacy of parents or caregiver, there will be likely poorer oral health outcomes (Miller et al., 2010) Another study conducted in which it is stated that a young child is not able to buy a toothbrush or visit to a dentist alone, so if the parents are not involved in the education process actively, the children will lead to a poor oral hygiene (Haats, R. 2012).

In the present study, educational intervention about oral care is effective and improve the oral health status of children who are involved in the study, and especially that student who perform practically in the front of an educator. The techniques of behavior modification are most effective because before the intervention most of the student doesn't know to brush the surface of the tongue and just $26.8 \%$ of students agree and brushing the surface of the tongue, but they don't know the proper way to brush the surface of the tongue, after the educational intervention $73.2 \%$ of students agree and brush the surface of the tongue by proper way. In the similar study, finding indicated that it's very necessary to clean the tongue for every person even if they don't know the benefit, brushing of the tongue decreased the volatile sulpher compound which is really effective in the treatment of halitosis. The study demonstrated that tongue is a potential reservoir for the bacteria mutans streptococci which are the cariogenic species in young children and its lead to be a predictive factor dental carries risk in school children, that it why it is suggested to clean their tongue by proper way (Dos Santos, Nadanovsky, \& De Oliveira, 2015).

In the present study, it is understood that educational intervention about oral care can easily motivate the school children and help them to know the proper way of brushing techniques. It is also found that lecturing method is a complex and time-saving procedure. Another study conducted which show that oral health education is very much important because its much effective and help in improving poor oral health status of school children by the help of different method like lecture method, practice, intervention, model or brochure. The same result to the present study was also found in test score in each group and study showed significant improvement in oral health hygiene and children's knowledge of oral health (Demiriz et al., 2018).

\section{Limitation}

The main limitation of this study was shortage of time and too much less sample size 56 due to which we cannot generalize this study on the whole population. 


\section{Conclusion}

It is concluded that educational intervention in primary school children is much effective to improve oral health care and appropriate behavior related to the practice of tooth brushing. Educational intervention related to oral care has the potential to make a great impact on the oral health of school children. The training of teachers and their motivation, both are needed for their role in oral health education. In this study, oral health education accomplishes a significant effect on primary school children.

\section{ACKNOWLEDGEMENT}

This research work was not possible without the help and encouragement of many individuals to whom I am really very grateful. First and foremost, I would like to thank Mr. Muhammad Afzal (The Principal of Lahore School of Nursing) who allowed me for this study. Sir Muhammad Hussain and Ms Irum Majeed, for being my preceptors and for being the greatest inspiration for my work when I had no idea to perform a research work, and who has been supportive and encouraging me throughout the whole process and freely offered their precious time to help me. Without their willingness to guide me in this study, this research work would not have come to completion. I am also grateful to my friends Naseemullah, M, Muneebullah Saif, M, Faisal Munir, Yasir Nouman, all class members and all those people who I contacted during this process. I also thank to the management of the university of lahore. Last but not the least, I would like to thank my parents, my elder brother, and my sweet Jiya Sana who provided endless moral, financial and motivational support for me during this research work.

\section{CONFLICT OF INTREST}

(None)

\section{FUNDING BODY}

(None)

\section{References}

Carvalho, T. H. L, Ppinheiro, N. M. S., Santos, J. M. A., Costa, L. E. D., Queiroz, F. S., \&Nobrega, C. B. c. (2016). Estrategias de prmocao de saude para criancas emidade pre-escolar do municipio de Patos- PB. Rev Odontol UNESP (Internet) , 42(6), 426-431 .

Casanova-Rosado, A. J., Medina-Solis, C. E., Casanova-Rosado J. F., Vallejos-Sanchez, A. A., Minaya-Sanchez, M., Mendoza-Rodriguez, M., . . Maupome, G. (2014). Tooth brushing frequency in Mexican schoolchildren and associated socio-demographic, socioeconomic, and dental variables. Medical science monitor: international medical journal of experimental and clinical research, 20, 938.

Cascaes, A. M., Peres, K. G., peres M. A., Demarco, F. F., Santos, I., Matijasevich, A., \&Barros, A.J. (2015). Validity of 5-year-old children's oral hygiene pattern referred by mothers. Revista de Saude Publica, 45(4), 668-675.

Dahl, K. E. (2011). Oral Health -related quality of life in Norwegian adults.

Demiriz, L., Dede, F. O., \& Balli, U. (2018). Impact of Three Different Education Methods on Oral Hygiene and Thoeratical Knowledge of Schoolchildren. Pesquisa Brasileira em Odontopediatria e Clinica INtegrarada, 18(1), 3897.

Habib, E., Shiraz, A., Naseri-Kouzehgarani, G., Hooman, S., \& Reza, M. (2016). The determinants of high school student's smooking habits with special focus on teacher's smooking in Iran: a population based study. Pneumologia (BucharestRomania), 61(1), 28-33.

Haleem, A., Siddiqui, M. I., \& Khan, A. A. (2012). School-based strategies for oral health education of adolescents-a cluster randomized controlled trial. BMC oral health, 12(1), 54.

Jurgensen, N., \& Petersen, P. (2014). Promoting oral health of children through schools-results from a WHO global survey 2012. Community Dent Health, 30(4), 204-218.

Macpherson, L., Anopa, Y., Conway, D., \& MchMahon, A. (2013). National supervised toothbrushing program and dental decay in Soctland. Journal of dental research, 92(2), 109-113.

Mohamadkhah, F., Shkravi, F. A., Karimy, M., \& Faghihzadeh, S. (2014). Effects of lecturing on selfcare oral health behaviors of elementary students. Medical journal of the Islamic Republic of Iran, 28, 86.

Raj, S., Goel, S., Sharma, V. L., \& Goel, N. K. (2016) Short-term impact of oral hygiene training package to Anganwadi workers on improving oral hygiene of preschool children in North Indian City. BMC Oral Health, 13(1), 67.

Reddy, M., \& Singh, S. (2017). The promotion of oral health-promoting schools in KwaZulu-Natal Province, South Africa. South African Journal of child health, 11(1), 16-20.

Rosema, N., Hennequin-Hoenderdos, N., Versteeg, P., van Palenstein Helderman, W., Van der Velden, U., \& Van der Weijden, G. (2013). Plaque-removing efficacy of new and used manual toothbrushes-a professional brushing study. International journal of dental hygiene, 11(4), 237-243. 
Sanadhya, Y.k., Thakkar, J. P., Divakar, D. D., Pareek, S., Rathore, K., Yousaf, A., Asawa, K. (2014). Effectivenes of oral health education on Knowledge, attitude, practices and oral hygiene status among 12-15-year old schoolchildren of fishermen of Kuch district, Gujrat, India. International maritime health, 65(3), 99-1-5

Shah, M. A., Darby, M., \& Bauman, D. (2015). Improving oral health in Pakistan using dental hygienists. International journal of dental hygiene, 9(1), 43-52.

Shah, M. N., Akhtar, S., Khan, M. A., \& Shah, F. (2015). Tooth brushing habits and knowledge among patient visiting Khyber College of dentistry. Cell, 333, 9131996.

Siguad, C. H. d. S., Santos, B. R. d., Costa, P., \& Toriyama, A. T. M. (2017). Promoting oral care in the preschool child: effects of a playful learning intervention. Revista brasileirade enfermagem, 70(3), 519-525.

Stein, C., Santos, N. M. L., Hilgert, J. B., \& Hugo, F. N. (2018). Effectiveness of oral health education on oral hygiene and dental caries in schoolchildren: Systematic review and meta-analysis. Community dentistry and oral epidemiology, 46(1), 30-37.

Twetman, S., \& Dhar, V. (2015). Evidence of effectiveness of current therapies to prevent and treat earlychildhood caries. Pediatric dentistry, 37(3), 266-253.

Younas, A., \& Qureshi, A. (2016). Tooth brush changing frequency and associated socio-demographic and oral hygiene factors among residents of Karachi. Journal of Dentistry and Oral Hygiene, 8(2), 4-11. 